\title{
Identification and cloning of the Type IIla plasmid- encoded dihydrofolate reductase gene from trimethoprim-resistant gram-negative bacteria isolated in Britain
}

\author{
C. J.THOMSON, K.J.TOWNER*, H.-K. YOUNG† and S. G. B. AMYES
}

Department of Bacteriology, The Medical School, University of Edinburgh, Teviot Place, Edinburgh EH8 9AG; "Department of Microbiology and PHLS Laboratory, University Hospital, Nottingham NG7 2UH; and tDepartment of Biological Sciences, University of Dundee, Dundee DD1 4HN

\begin{abstract}
Summary. A clinical strain of Escherichia coli isolated in Nottinghamshire in 1980 was shown to harbour the type IIIa trimethoprim-resistant dihydrofolate reductase gene, previously identified on only one occasion, in New Zealand in 1979. The gene was identified by hybridisation with an 855-bp type III gene probe and its classification as a type IIIa dihydrofolate reductase was confirmed by detailed biochemical analysis of the enzyme product. The dihydrofolate reductase was identical in size and isoelectric point with the original type IIIa enzyme and shared similar inhibitory and kinetic profiles. The trimethoprim resistance gene was subsequently cloned and the type IIIa dihydrofolate reductase gene was localised to a 700-bp EcoRI-PstI fragment. This smaller fragment may prove to be a more specific DNA probe for the future identification of type IIIa dihydrofolate reductase genes.
\end{abstract}

\section{Introduction}

The synthetic antimicrobial agent trimethoprim (Tp) selectively inhibits the bacterial enzyme dihydrofolate reductase (DHFR) (5,6,7,8-tetrahydrofolate: NADP ${ }^{+}$oxidoreductase, EC1.5.1.3) which catalyses the reduction of dihydrofolate to tetrahydrofolate, an essential cofactor involved in the biosynthesis of purines, pyrimidines and amino acids. Resistance to trimethoprim mediated by resistance plasmids ( $R$-plasmids), was first reported by Fleming et al. ${ }^{1}$ The mechanism of resistance involves the plasmid-encoded synthesis of an additional trimethoprim-resistant dihydrofolate reductase which enables the inhibited host enzyme to be by-passed. ${ }^{2}$

Seven major types of plasmid DHFRs present in gram-negative bacteria have been characterised on the basis of their biochemical properties (see review) ${ }^{3}$ They vary in molecular size, heat lability, antifolate sensitivities and Michaelis Menten kinetics. Specific gene probes have now been developed which can identify several of the genes

Received 3 July 1989 ; accepted 2 Oct. 1989.

¥ Correspondence should be sent to Dr S. G. B. Amyes, Department of Bacteriology, The Medical School, University of Edinburgh, Teviot Place, Edinburgh EH8 9AG. encoding the various enzyme types (see Materials and methods).

Strains producing each of the enzyme types I, II, V, VI and VII exhibit a characteristically high level of resistance to trimethoprim-minimum inhibitory concentration (MIC) $>1000 \mathrm{mg} / \mathrm{L}$. In contrast, strains producing the types III and IV plasmid DHFRs are only moderately resistant to trimethoprim (MIC $\leqslant 64 \mathrm{mg} / \mathrm{L})$. Unlike other plasmid DHFRs, the type III and IV enzymes are only slightly more resistant than the Escherichia coli chromosomal DHFR to the inhibitory action of trimethoprim $(\mathrm{Ki}=19 \mathrm{nM}$ and $63 \mathrm{nM}$ respectively). ${ }^{4,5}$

The gene encoding the prototype type III enzyme (now designated type IIIa) was found on a single plasmid (pAZ1) originating in a clinical isolate of Salmonella typhimurium in New Zealand in $1979 .{ }^{6}$ Two other biochemically similar plasmid-encoded enzymes (types IIIb and IIIc) have recently been reported in Shigella strains isolated in the USA. ${ }^{7}$ The other moderately resistant DHFR gene, type IV, has been identified on several different plasmids, all of which originated in clinical isolates of bacteria in Southern India. ${ }^{8}$

In this paper we describe the identification of the type IIIa plasmid-encoded DHFR in bacteria isolated in Great Britain. This is the first report of 
the type IIIa trimethoprim resistant DHFR since its original discovery in New Zealand in 1979.

\section{Materials and methods}

\section{Bacterial strains and plasmids}

E. coli TM858 $\left(\mathrm{Tp}^{\mathrm{r}}\right)$ was isolated in 1980 from a urine specimen from a hospitalised patient in Nottingham. Trimethoprim resistance was mobilised, in bacterial conjugation experiments, to E. coli $\mathrm{K} 12$ strain $\mathrm{J} 53-2$, following transposition on to the inc $\mathrm{P}$ group plasmid RP4 as previously described. ${ }^{9}$ Control plasmids encoding previously characterised DHFRs were as follows: R483 (type Ia); pUK 163 (type Ib); R67 (type IIa); R388 (type IIb); R751 (type IIc); pFE1242 (type IIIa); pUK1123 (type IV); and pLK09 (type V) (see review). ${ }^{10}$ All the plasmids were carried by $E$. coli $\mathrm{K} 12$ derivatives. Plasmid DNA was isolated as described previously. ${ }^{11}$ DNA probes specific for known DHFR genes comprised the following : 499-bp HpaI fragment of pFE872 (type I) ${ }^{12}$ 275-bp Sau3A-EcoRI fragment of pWZ820 (type II) ${ }^{13}$ 855-bp EcoRI-HindIII fragment of pFE1242 (type III) (M. E. Fling, personal communication); 1.7-kb ClaI fragment of pUK1148 (type IV); ${ }^{14}$ 500-bp HincII fragment of pLK09 (type V). ${ }^{14}$ Probes were isolated and labelled with biotin-11-dUTP as described by Towner $e t$ $a l .{ }^{14}$ Cloning procedures were as described by Maniatis et al. ${ }^{15}$

\section{MIC determination}

The MIC of trimethoprim for $E$. coli strains was determined on Diagnostic Sensitivity Test Agar (DSTA; Oxoid) as described previously. ${ }^{8}$

\section{Hybridisation}

Plasmid DNA was isolated on agarose gels and transferred to nitrocellulose filters with a Semidry Electroblotter (Sartorius Ltd) as described previously. ${ }^{14}$ Hybridisation conditions were those of Carter et al., ${ }^{11}$ with detection of a positive hybridisation result by means of a BlueGENE kit (Bethesda Research Laboratories Ltd); the conditions and protocols used were those recommended by the manufacturer.

\section{Enzyme preparation and assay}

DHFR was prepared from 2-L overnight cultures of bacteria grown in IsoSensitest Broth (Oxoid) with vigorous agitation at $37^{\circ} \mathrm{C}$, as described by Young and Amyes. ${ }^{5}$ The cells were harvested by centrifugation $\left(6000 \mathrm{~g}, 10 \mathrm{~min}, 15^{\circ} \mathrm{C}\right)$ and re-suspended in buffer $\mathrm{A}$

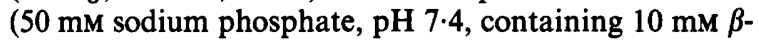
mercaptoethanol and $1 \mathrm{mM}$ EDTA). The bacteria were disrupted by sonication and the cell debris was removed by centrifugation $\left(40000 \mathrm{~g}, 1 \mathrm{~h}, 4^{\circ} \mathrm{C}\right)$. DHFR activity was assayed at $37^{\circ} \mathrm{C}$ in $40 \mathrm{~mm}$ sodium phosphate buffer, pH 6.0, as described previously. ${ }^{2}$ One unit of DHFR activity was defined as the amount of enzyme required to reduce $1 \mathrm{nmol}$ of dihydrofolate/min. Ammonium sulphate was added to $50 \%$ saturation. After centrifugation (14 $000 \mathrm{~g}, 30 \mathrm{~min}, 4^{\circ} \mathrm{C}$ ), further ammonium sulphate was added to the supernate to give $80 \%$ saturation and, following further centrifugation, the pellet was dialysed against buffer $A$. It was applied to a Sephadex G-75 column $\left(2 \mathrm{~cm}^{2} \times 90 \mathrm{~cm}\right)$ previously equilibrated with buffer $A$ and eluted with the same buffer. Molecular mass was determined by Sephadex exclusion chromatography as described previously. ${ }^{2}$ Heat sensitivity, enzyme kinetics and inhibitor studies were performed as previously described. ${ }^{16}$

\section{Iso-electric focusing of DHFRs}

Iso-electric focusing was performed by a modification of the method of Broad and Smith $;{ }^{17}$ 10- $\mu$ l volumes of the re-suspended and dialysed $80 \%$ saturation ammonium sulphate pellet were applied to the surface of standard LKB polyacrylamide plates containing ampholines capable of producing a gradient from $\mathrm{pH} 3.5$ to 9.5 (no. 1804-101). Standard pI markers were also applied to each gel. Samples were focused for $6 \mathrm{~h}$ on a cooled $\left(9^{\circ} \mathrm{C}\right)$ LKB Ultrophor electrophoresis system (no. 2217) at $500 \mathrm{~V}$ and $20 \mathrm{~mA}$, limited by constant power at $1 \mathrm{~W}$. The gels were stained for DHFR activity by the method of Broad and Smith. ${ }^{17}$

\section{Results}

\section{Identification and cloning of the type IIIa DHFR gene}

$E$. coli TM858 was isolated from the urine of a hospitalised patient in Nottinghamshire in 1980. This strain was highly resistant to trimethoprim (MIC $>1024 \mathrm{mg} / \mathrm{L}$ ). Trimethoprim resistance was not freely transferable and could be mobilised to $E$. coli $\mathrm{K} 12$ strain $\mathrm{J} 53-2$ only following transposition on to plasmid RP4. The resulting transconjugant, E. coli J53-2 (pUN635=RP4 :: Tn3175), was also highly resistant to trimethoprim (MIC> $>1024 \mathrm{mg} /$ L). Therefore, purified plasmid DNA was hybridised with those gene probes known to identify high level trimethoprim resistance genes (i.e., DHFR types I, II and V gene probes). However no hybridisation occurred with any of these probes, which indicated the presence of a novel DHFR gene.

To expedite a more detailed analysis of the trimethoprim resistance gene and its product, the trimethoprim resistance gene of strain J53-2 (pUN635) was cloned into the vector plasmid 

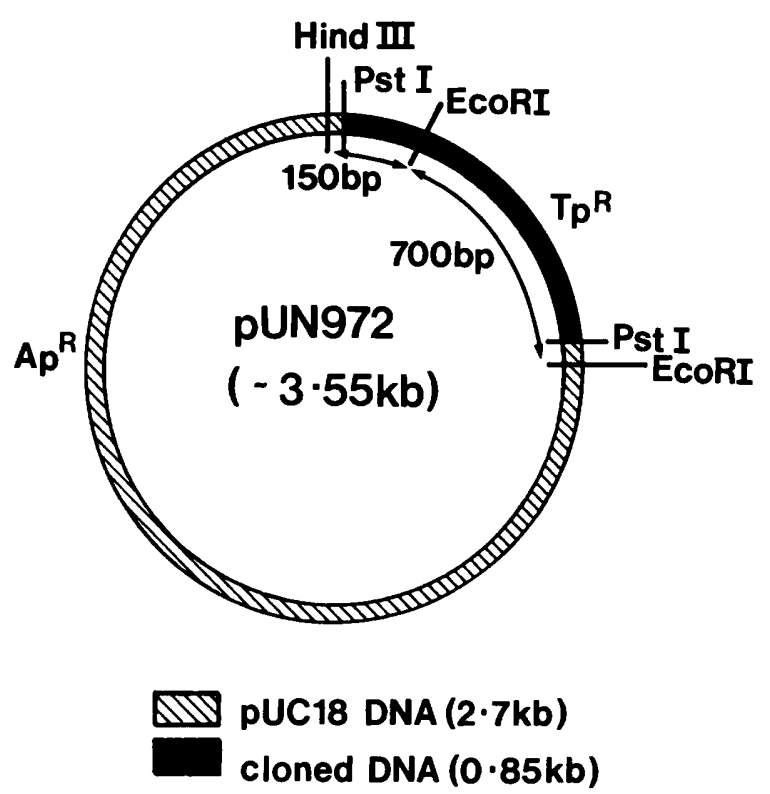

Fig. 1. Restriction map of recombinant plasmid pUN972 carrying the type IIIa DHFR.
pUC18. Plasmid pUN635 was digested with the restriction enzymes $P$ st $I$ and the resulting fragments were ligated into $\mathrm{pUC18}$. The recombinant plasmids were then introduced by transformation into E. coli $\mathrm{HB} 101$ and selection was made for trimethoprim-resistant colonies on DSTA containing trimethoprim $50 \mathrm{mg} / \mathrm{L}$. A single trimethoprimresistant clone was obtained which was found to contain an $0.85-\mathrm{kb}$ PstI fragment ligated to $\mathrm{pUC18}$. This recombinant plasmid was designated pUN972 (fig. 1). The MIC of trimethoprim for HB101 (pUN972) was found to be $64 \mathrm{mg} / \mathrm{L}$, much lower than the original pUN635-containing bacteria.

Plasmid pUN972 was hybridised with all available plasmid DHFR gene probes. A positive hybridisation result was obtained only with the type IIIa DHFR gene probe. Further evidence suggesting that pUN972 carried a type IIIa DHFR gene was obtained when a $0.7-\mathrm{kb}$ EcoRI-PstI fragment of pUN972 (fig. 1), carrying the trimethoprim resistance gene, was used to probe control plasmids encoding previously characterised DHFRs. Hybridisation was detected only with the original type IIIa DHFR-encoding plasmid, pAZ1.

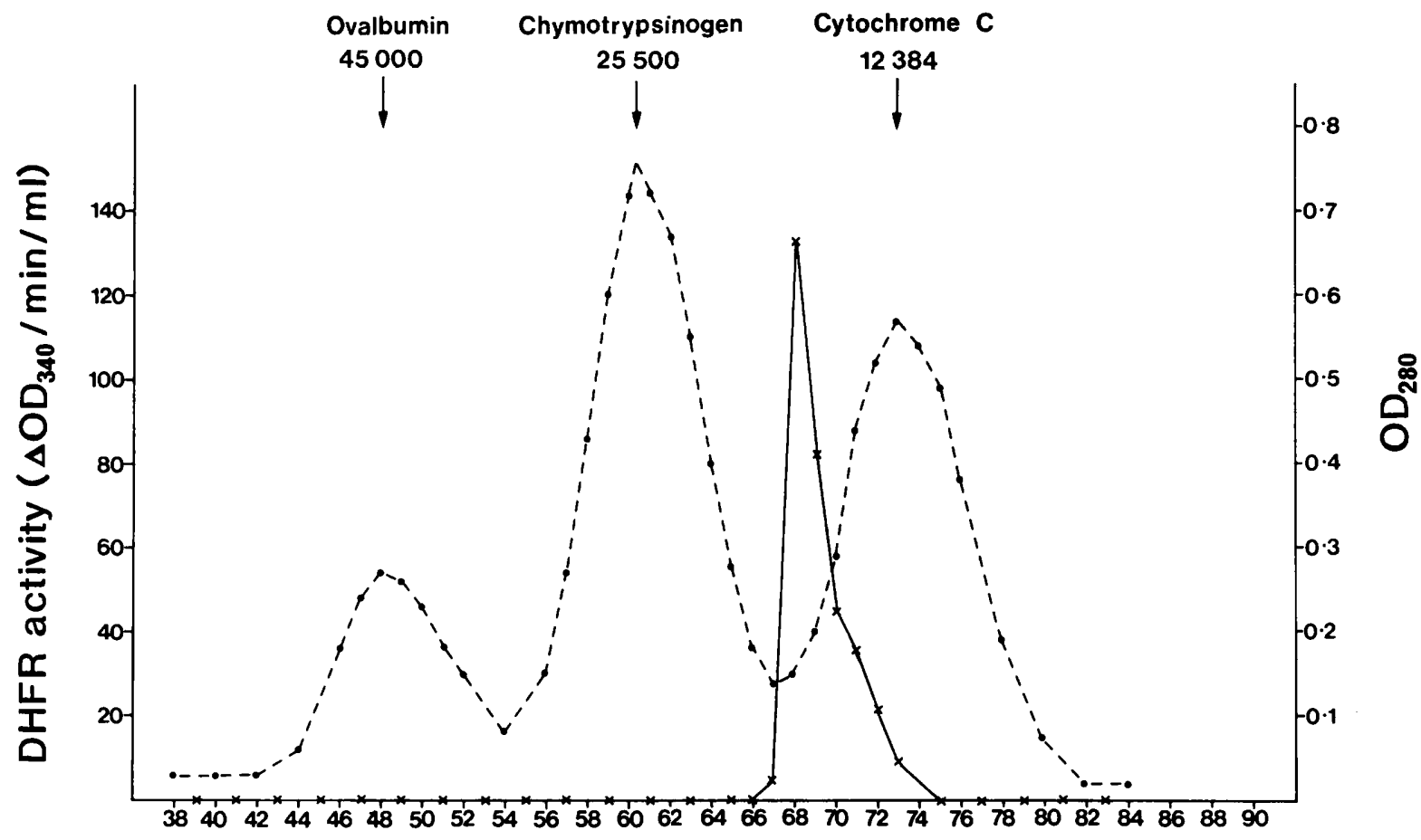

\section{Fraction number}

Fig. 2. Sephadex G-75 gel filtration of the type IIIa DHFR. $\times-\times$, DHFR activity obtained after sephadex exclusion chromatography of a 50-80\% saturation ammonium sulphate precipitate from $E$. coli HB101 (pUN972). $\bullet-\ldots,-\bullet$, Elution of standard marker proteins $\left(\mathrm{OD}_{280}\right)$. 


\section{Purification of the DHFR encoded by pUN972}

DHFR activity was purified from $2 \mathrm{~L}$ of culture. After removal of nucleic acids with streptomycin sulphate, the protein was selectively precipitated with ammonium sulphate between 50 and $80 \%$ saturation. The precipitated protein was dialysed against buffer $\mathrm{A}$ and applied to a pre-calibrated Sephadex G-75 column. A major DHFR peak was eluted during gel filtration corresponding to a molecular weight of 17000 daltons (fig. 2). This is indistinguishable from the 16900 daltons reported for the original type IIIa enzyme encoded by plasmid pAZ1.

\section{Characterisation of the pUN972 and $p A Z 1$ encoded DHFRs}

Inhibitor profiles. To compare the pUN972encoded enzyme with the original type IIIa enzyme, the DHFR encoded by pAZ1 was also purified and separated by gel filtration of Sephadex G-75. Fractions containing peak DHFR activity were pooled for each enzyme preparation and used for comparative characterisation.

Both enzymes were found to be heat stable, they retained more than $50 \%$ activity after being held at $45^{\circ} \mathrm{C}$ for $12 \mathrm{~min}$. Partially purified DHFR activity was assayed in the presence of increasing concentrations of trimethoprim and methotrexate. Both enzymes were approximately 10 times more resistant to inhibition by trimethoprim than the $E$. coli chromosomal DHFR, losing $50 \%$ of their activity in the presence of $4.5 \mu \mathrm{M}$ trimethoprim. This is also similar to the value previously reported by Joyner et $a l .{ }^{4}$ for the pAZ1-encoded enzyme. Similarly, both enzymes were inhibited by $50 \%$ in the presence of 10 times greater concentrations of methotrexate $(0.02 \mu \mathrm{M})$ than that required to inhibit the $E$. coli chromosomal enzyme.

Michaelis Menten kinetics. The activity of the pUN972 encoded enzyme was investigated in conditions of partial saturation with dihydrofolate and the results were analysed by the method of Lineweaver and Burk (fig. 3). The results (fig. 3)

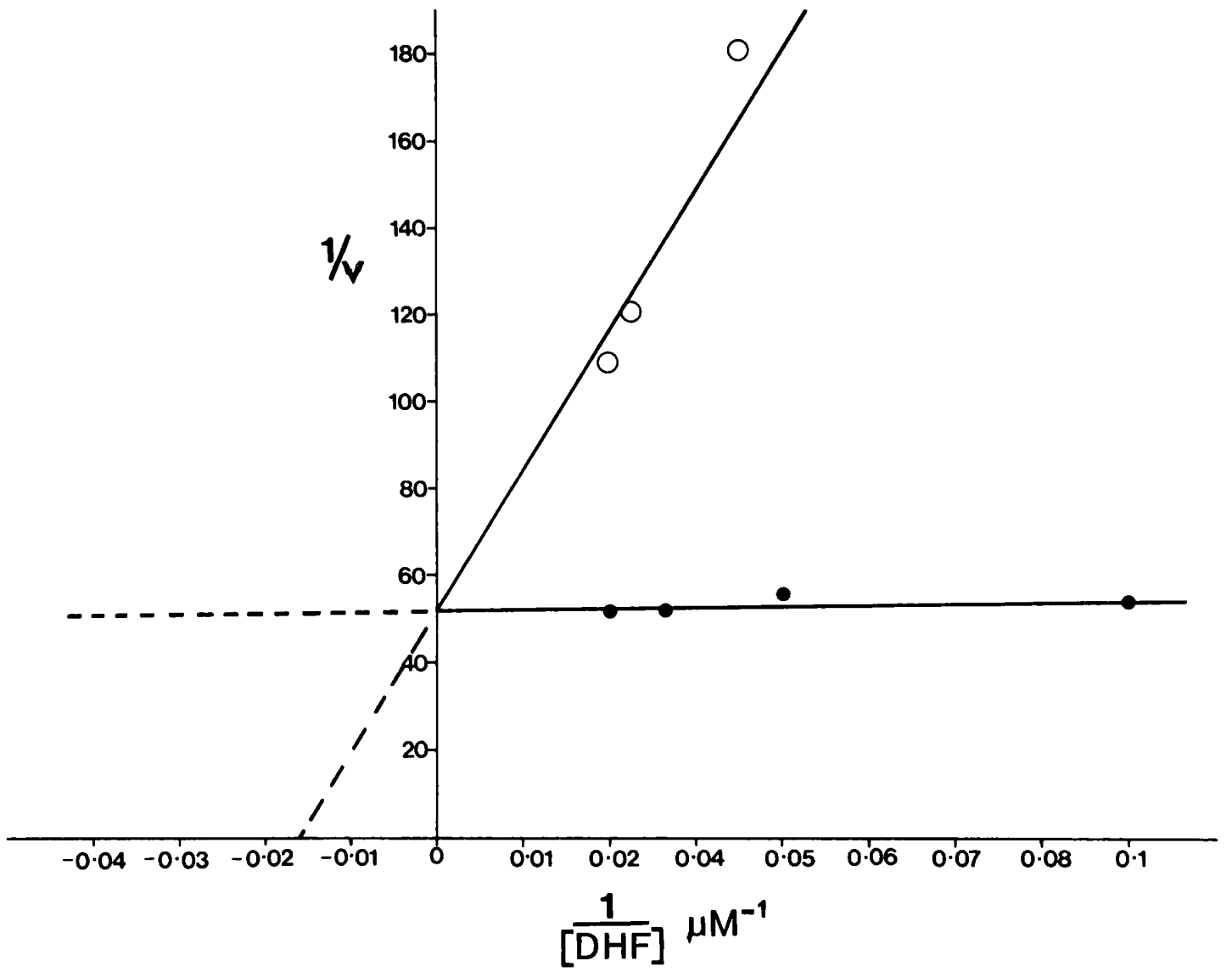

Fig. 3. Lineweaver-Burk plots of the partially purified type IIIa DHFR. The reciprocal of the dihydrofolate concentration (1/[DHF]) is plotted against the reciprocal of the rate of DHFR activity $(1 / \mathrm{V})$ in the presence and absence of trimethoprim. $\bullet$, No trimethoprim; $\circ, 5 \mu \mathrm{M}$ trimethoprim. 
show that the $\mathrm{Km}$ value for dihydrofolate was $0.41 \mu \mathrm{M}$, a value similar to that previously published for the pAZ1 encoded enzyme. When the assays were repeated in the presence of trimethoprim it was found that the maximum velocity remained the same (fig. 3), indicating that the drug causes competitive inhibition of the enzyme. The inhibitor constant $(\mathrm{Ki})$ for trimethoprim was $0.04 \mu \mathrm{M}$, again similar to that reported for the pAZ1-encoded, type IIIa DHFR.

Iso-electric focusing. Final evidence indicating that the pUN972-encoded dihydrofolate reductase was identical to the type IIIa enzyme encoded by pAZ1 was obtained by determination of the isoelectric point of the two enzymes. When run concurrently, both enzymes were found to co-focus with a $\mathrm{pI}$ of $6 \cdot 1$, thus confirming the classification of the pUN972-encoded enzyme as a type IIIa DHFR (fig. 4).

\section{Discussion}

The original strain of $E$. coli studied in this paper exhibited high level resistance to trimethoprim, characteristic of plasmid DHFR types I, II, V, VI and VII. However, hybridisation studies employing the available DNA probes specific for these DHFR gene types failed to identify a previously characterised DHFR gene. Further genetic analysis, involving cloning of the trimethoprim resistance gene into the vector plasmid pUC18, revealed a DHFR gene conferring only a moderate level of trimethoprim resistance in the recombinant strain. Detailed biochemical analysis of the enzyme product of this gene showed it to be identical with the type IIIa enzyme, encoded by pAZ1, described by Fling et $a l .{ }^{6}$ This is the first report of the type IIIa DHFR gene since its original detection in a clinical isolate in New Zealand.

One interesting feature of this work is the apparent reduction in MIC of trimethoprim for the strain carrying the cloned type IIIa DHFR compared to the original isolate. One possible explanation is that a second DHFR gene, conferring a high level of resistance, was present on the original transposon and that this "masked" the presence of the low level type IIIa determinant; however, other more complicated scenarios involving gene copy numbers or gene regulation are perhaps more feasible. For example, the MIC could vary depending on the orientation of the insert and whether the gene was utilising its own promotors or those of pUC18.

An important consequence of this study has been

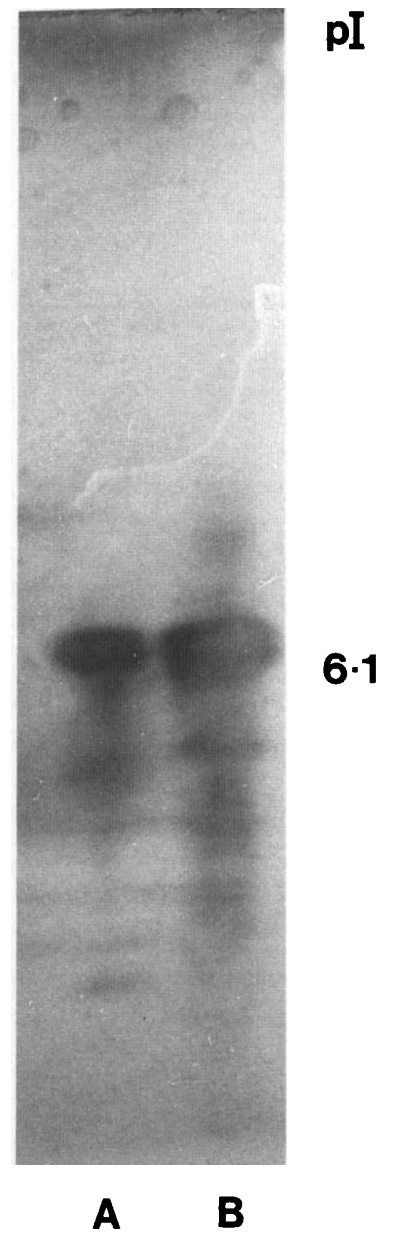

Fig. 4. Iso-electric focusing pattern of the type IIIa DHFRs. Track A, type IIIa enzyme originally obtained from plasmid pAZ1 (New Zealand); track B, type IIIa enzyme obtained from plasmid pUN972 (Nottingham).

the production of a new type IIIa DHFR gene probe. The previously available $855-b p$ DNA probe for the type IIIa gene contains approximately $350 \mathrm{bp}$ extraneous to the structural gene $;{ }^{18}$ consequently it has been shown to produce occasional "false positive" hybridisation reactions (K. J. Towner, unpublished results). The gene probe constructed in this study is smaller $(700 \mathrm{bp})$ and may prove, therefore, to be more specific. The elaborate techniques involved in the detection and confirmation of the type IIIa DHFR gene suggest that the apparent low incidence of the type IIIa enzyme may result from a lack of detection rather than a scarcity of the gene. Therefore, the new gene probe constructed in this study may be very useful 
in clarifying the epidemiology of what has previously been considered to be an extremely unusual resistance gene.

\section{REFERENCES}

1. Fleming M P, Datta N, Grüneberg $R$ N. Trimethoprim resistance determined by $\mathrm{R}$ factors. $\mathrm{Br}$ Med J 1972; 1 : 726-728.

2. Amyes S G B, Smith J T. R-factor trimethoprim resistance mechanism: an insuceptible target site. Biochem Biophys Res Commun 1974; 58: 412-418.

3. Amyes S G B. The success of plasmid-encoded resistance genes in clinical bacteria. $J$ Med Microbiol 1989; 28 : 73-83.

4. Joyner S S, Fling M E, Stone D, Baccanari D P. Characterisation of an R-plasmid dihydrofolate reductase with a monomeric structure. J Biol Chem 1984; 259: $5851-5856$

5. Young H-K, Amyes S G B. A new mechanism of plasmid trimethoprim resistance: characterisation of an inducible dihydrofolate reductase. J Biol Chem 1986; 261 : 2503-2505.

6. Fling M E, Walton L, Elwell L P. Monitoring of plasmidencoded, trimethoprim-resistant dihydrofolate reductase genes: detection of a new resistant enzyme. Antimicrob Agents Chemother 1982; 22: 882-888.

7. Barg N, Hutson F, Amyes S G B, Thomson C J, Wharton M, Schaffner W. Two outbreaks of dysentery caused by antibiotic resistant Shigella sonnei (ARS) elaborating a type III dihydrofolate reductase (DHFR). Abstracts of the Annual Meeting of the American Society of Microbiology 1988; no. C-108.

8. Young H-K, Jesudason M V, Koshi G, Amyes S G B. Unusual expression of new low-level trimethoprim resistance plasmids. $J$ Clin Microbiol $1986 ; 24$ : 61-64.

9. Towner K J, Venning B M, Pinn P A. Occurrence of transposable trimethoprim resistance in clinical isolates of Escherichia coli devoid of self-transmissible resistance
We thank the Wellcome Trust for grant no. 16376/1.5, the Trent Regional Health Authority and the Society for General Microbiology for the support of this work.

plasmids. Antimicrob Agents Chemother 1982; 21 : 336338.

10. Huovinen P. Trimethoprim resistance. Antimicrob Agents Chemother $1987 ; 31$ : 1451-1456.

11. Carter G I, Towner K J, Slack R C B. Rapid detection of a specific trimethoprim resistance gene using a biotinylated DNA probe. J Antimicrob Chemother 1987; 20: 335-341.

12. Fling $M E$, Richards $C$. The nucleotide sequence of the trimethoprim-resistant dihydrofolate reductase gene harbored by Tn7. Nucleic Acids Res 1983; 11 : 51475158.

13. Zolg J W, Hänggi $U \mathbf{J}$, Zachau $H$ G. Isolation of a small DNA fragment carrying the gene for dihydrofolate reductase from a trimethoprim resistance factor. $\mathrm{Mol}$ Gen Genet 1978; 164: 15-29.

14. Towner K J, Young H-K, Amyes S G B. Biotinylated DNA probes for trimethoprim-resistant dihydrofolate reductases types IV and V. J Antimicrob Chemother 1988; 22: 285-291.

15. Maniatis T, Fritsch E F, Sambrook J. Molecular Cloning; A Laboratory Manual. Cold Spring Harbor, Cold Spring Harbour Laboratory, 1982.

16. Amyes S G B, Smith J T. The purification and properties of the trimethoprim-resistant dihydrofolate reductase mediated by the R-factor, R388. Eur J Biochem 1976; 61 : 597-603.

17. Broad D F, Smith J T. Classification of trimethoprim resistant dihydrofolate reductase mediated by $\mathbf{R}$ plasmids using isoelectric focusing. Eur $J$ Biochem $1982 ; 125$ : 617-622.

18. Fling M E, Kope J, Richards C. Characterisation of plasmid pAZ1 and the type III dihydrofolate reductase gene. Plasmid 1988; 19: 30-38. 